\title{
Mini-grid hybridization and demand side management on non- interconnected small islands: the case study of Ustica, Italy
}

\author{
Paolo Cherubini ${ }^{1 *}$, Guido Francesco Frate ${ }^{1}$, Marco Antonino Maggiore ${ }^{2}$, Andrea Micangeli ${ }^{2}$, Lorenzo Ferrari ${ }^{1}$ \\ ${ }^{1}$ DESTEC, University of Pisa, Largo Lucio Lazzarino, Pisa 56122, Italy \\ ${ }^{2}$ DIMA, Sapienza University of Rome, Via Eudossiana 18, Rome 00184, Italy
}

\begin{abstract}
Small Mediterranean islands are typically served by mini-grids based on inefficient, polluting and costly diesel generators that provide electricity and freshwater through desalination plants. The study focuses on the case study of the Italian island of Ustica, for which the actual consumption and generation load profiles for 2018 have been used to simulate different scenarios through HOMER Pro software. The scenarios tested the possible integration of renewable energy sources (photovoltaic, small wind turbines) and electrochemical storage in the system, based on a techno-economic, financial, and environmental analysis. In addition to generation-side interventions, demand-side management strategies have been evaluated by considering the desalter as a deferrable load and by introducing energy efficiency measures. Finally, a sensitivity analysis on the most influential parameters (diesel price, discount rate) has been conducted on the base case scenario. The proposed technical solutions are compatible with the environmental and regulatory constraints of the island and lead to reduced emissions and long-term savings. The savings would enable a reduction in the cross-subsidy that the mainland electricity users pay to cover the higher costs incurred for diesel generation in non-interconnected small islands.
\end{abstract}

\section{Introduction}

There is a pressing need issued by the international community to transform the global energy system to contrast climate change, reducing carbon emission by mainstreaming renewable energy sources and increasing energy efficiency [1]. For electricity generation, minigrids are considered to be a key part of this transformation process, as they can harness decentralized energy sources to serve local loads in a standalone mode, but can also be interconnected to a wider grid, increase the flexibility of operations, security of supply and reducing dependency on fossil fuels [2]. Electricity systems in small islands are often standalone mini-grids which, in certain cases, may be interconnected between each other or to the mainland. It has been estimated that there are more than 2000 small islands worldwide, inhabited by 21 million people and consuming $\sim 52.7$ TWh of electricity per year, typically produced by diesel generators [3]. In addition to the detrimental effects on the environment, dependency on fuel-fired generators entails high import costs, subject to high price volatility, and risk of energy insecurity, especially if the generation mix is not diversified. Moreover, energy is closely related to access to water, as it can be produced in place with clean, electricity- powered desalination processes, such as reverse osmosis [4]; otherwise, in the absence of natural sources or underwater pipelines connected to the mainland, water has to be delivered with tankers.

In the European Union, an initiative to support a sustainable transition for EU islands was launched in 2017 within the 'Clean Energy for all Europeans' program [5]. A successful implementation example of a hybrid, interconnected smart grid integrating wind, solar, electrochemical storage and diesel backup comes from the island of Tilos, in Greece [6]. One of the typical challenges of small islands with a touristic vocation, like Tilos, is the huge seasonal variation of the population [6], causing spikes in electricity and water consumption during summertime, thus requiring the installation of oversized and redundant generation facilities [7].

These obstacles also characterize the twenty noninterconnected Italian small islands, with a total resident population of 56,000 inhabitants. In twelve of them, electricity is provided by small, vertically integrated companies, called Imprese Elettriche Minori (IEM) [8]. Due to dependency on diesel generators and minimal renewable penetration, the production cost per $\mathrm{kWh}$ is high, sometimes 6 times higher than the national one [8].

As a consequence of the price ceiling for the customers living on these islands, the extra-costs

\footnotetext{
*Corresponding author: paolo.cherubini@ing.unipi.it
} 
incurred by the local monopolies are recovered through a regulated remuneration rate, financed through the 'system charges' component of the electricity bill paid by the mainland consumers, which amounted to a 70 million euros subsidization for IEM in 2018 [8].

A major barrier for the implementation of renewable generation facilities, and wind turbines in particular, stems for the 'high natural interest' status of the islands, making them protected areas with strict landscape preservation policies [7]. Nonetheless, in 2017, the Italian Ministry for Economic Development (MISE) established a set of targets and incentives, both for citizens and IEM, to harness renewable energies [9].

In this paper, the island of Ustica will be considered as a case study. After analyzing the current mini-grid system, the available renewable resources and the regulatory and environmental constraints, a set of simulations developed with HOMER Pro are presented, with different scenarios involving the integration of renewable energy sources, electrochemical storage and water storage, the latter being modelled considering the desalination plant as a deferrable load. Finally, a sensitivity analysis on economic and financial parameters is performed.

\section{Case Study: Ustica Island}

Ustica is one of the smaller, non-interconnected Italian islands located in the Mediterranean Sea, along the Sicilian coast, about 36 nautical miles from the coast of Palermo, with an area of only 8.5 square kilometres, has a registered resident population of 1307 inhabitants [8], but the actual inhabitants may decrease in low season months, and have a two- or three-fold increase at the peak of the touristic season [10].

\subsection{Existing diesel-powered mini-grid and desalination plant}

The power plant of the island was firstly installed in 1933, and currently consists of five generators powered by diesel fuel, for an installed electrical power of about 6 MVA. In 2018, electricity consumption amounted to about $6 \mathrm{GWh}$; the breakdown of monthly consumption data by type is presented in Fig. 1 for the same year.

The seasonal pattern shows that, in August, the consumption is more than doubled with respect to low season months. Furthermore, $30 \%$ of the consumption is attributable to the desalination plant, the most energyintensive load on the island.

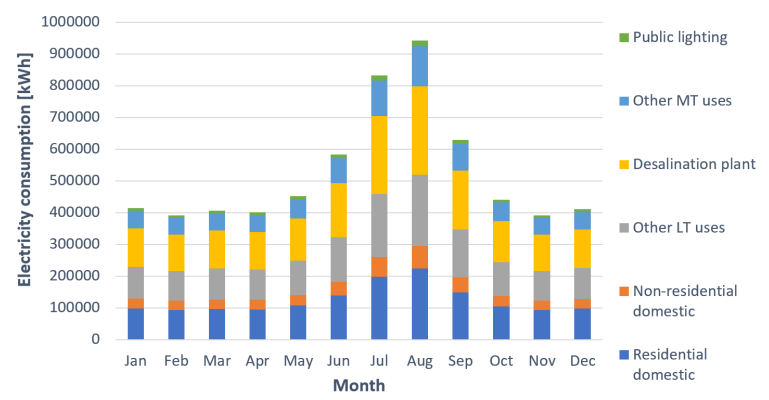

Fig. 1 Distribution of monthly electricity consumption in 2018
Desalination, formerly based on a thermal process, has been converted to Reverse Osmosis (RO) in 2015. The new plant has an average specific consumption of about $7 \mathrm{kWh} / \mathrm{m}^{3}$, which includes the treatment unit and the $60 \mathrm{~kW}$ pump that draws seawater to the plant, located at a $800 \mathrm{~m}$ distance and $90 \mathrm{~m}$ geodetic height from the intake.

The five fuel-fired generators, commissioned between 1988 and 2008, achieve a combined capacity of 4.7 MW. In Table 1 their specs and average operating loads and consumptions for 2018 are reported, showing limited exploitation and coordination of the units, which could be improved by adopting advanced, predictive dispatching strategies [11], [12].

Current renewable exploitation includes $105 \mathrm{~kW}$ of PV panels and a $24 \mathrm{~m}^{2}$ area of solar collectors for domestic hot water, which represent the $37.5 \%$ and $6.5 \%$ of the respective installation targets $(280 \mathrm{~kW}$ and $370 \mathrm{~m}^{2}$ ) set out for the island by MISE [9].

Table 1 - Diesel generators installed in Ustica

\begin{tabular}{|c|c|c|c|c|c|}
\hline $\begin{array}{c}\text { ID. } \\
\text { Group }\end{array}$ & $\begin{array}{c}\text { Rated } \\
\text { Power } \\
{[\mathrm{kW}]}\end{array}$ & $\begin{array}{c}\text { Equivalent } \\
\text { hours in 2018 } \\
{[\mathrm{kWh} / \mathrm{kW}]}\end{array}$ & $\begin{array}{c}\text { Average } \\
\text { operating } \\
\text { load [\%] }\end{array}$ & $\begin{array}{c}\text { Average } \\
\text { consump } \\
\text { tion } \\
{[\mathrm{l} / \mathrm{hour}]}\end{array}$ & $\begin{array}{c}\text { Specific } \\
\text { average } \\
\text { consumption } \\
{[\mathrm{kg} / \mathrm{MWh}]}\end{array}$ \\
\hline GR.1 & 700 & 3037 & $74.9 \%$ & 133 & 236,5 \\
\hline GR.2 & 1020 & 2017 & $64.7 \%$ & 179 & 234,8 \\
\hline GR.3 & 648 & 1446 & $58.4 \%$ & 104 & 241,5 \\
\hline GR.4 & 700 & 2557 & $73.9 \%$ & 132 & 236,6 \\
\hline GR.5 & 1600 & 1704 & $70.1 \%$ & 296 & 235,9 \\
\hline
\end{tabular}

\subsection{Renewable sources}

The PV irradiation for Ustica has been estimated with the PVGIS database. Only the unoccupied rooftops and areas outside the environmental reserve have been considered to obtain a realistic estimate for the surface actually available for PV modules, considering the regulatory constraints. An estimate of 2.4 MW has been set as the upper limit for PV installation by examining topographic maps and aerial pictures.

Wind resource data has been obtained from the local meteorological station and adjusted for height and roughness through Hellmann's model.

\section{Methodology}

The consumption, generation and renewable potential data has been used to run simulations in HOMER Pro, an established mini-grid optimization tool [13], which can integrate DSM strategies such as load deferral [14], and is tested for applications to Mediterranean islands, including the case of Ustica [15].

For the same case study, the authors in [16] developed a tailored multi-objective optimization procedure, that included the optimal operation of the desalination plant. Here, a simplified, broader, system approach is followed in order to compare different technical solutions under various financial and economic scenarios.

Firstly, a Base Case (BC) scenario was developed by simulating the current system, with the generation assets 
described in Table $\mathbf{1}$, in order to reproduce the 'business-as-usual' scenario to be used as a benchmark. Then, different generation-side interventions have been tested, considering different technology mix scenarios, combining PV, wind and electrochemical storage.

Subsequently, a demand-side intervention is evaluated in combination with selected renewable generation scenarios by setting the desalination plant as a deferrable load.

The capital and O\&M costs for the technologies used in the scenarios are reported in Table 2.

Table 2 - Capex and O\&M costs of components

\begin{tabular}{|c|c|c|}
\hline Component & CAPEX & O\&M \\
\hline PV & $1400 € / \mathrm{kW}$ & $28 € / \mathrm{kW} / \mathrm{y}$ \\
\hline Diesel Genset & - & $0.1 € / \mathrm{op} . \mathrm{hr}$ \\
\hline Wind Turbine & $2000 € / \mathrm{kW}$ & $60 € / \mathrm{kW} / \mathrm{y}$ \\
\hline Li-ion batteries & $400 € / \mathrm{kWh}$ & $15 € / \mathrm{kWh} / \mathrm{y}$ \\
\hline PCS & $300 € / \mathrm{kW}$ & - \\
\hline
\end{tabular}

The cost of PV was extrapolated from estimates in the Action Plan for Sustainable Energy (PAES) issued by Ustica municipality, inclusive of the conversion system at the residential scale [17]. Notwisthanding the decentralized domestic nature of the PV installation, power conversion system (PCS) costs were included conservatively to account for possible infrastructural adaptation at the network level. CAPEX for wind turbines was obtained averaging prices of sub- $100 \mathrm{~kW}$ units commercialized in Italy, and that for Li-ion batteries has been set according to similar projects developed in other non-interconnected Italian small islands.

Since no other diesel generators are envisaged to be added, for the existing ones only the O\&M cost was considered, and was set to calibrate the simulated Base Case scenario, in order to obtain the same Levelized Cost of Electricity (LCOE) of $0.326 € / \mathrm{kWh}$ that was calculated from the actual mini-grid data.

For the other O\&M costs, the values reported in the HOMER Pro library database that were deemed most appropriate have been considered.

An underlying assumption for the investment scenarios is that an electricity company operates as an Energy Service Company (ESCO), which will assume the commitment and costs of installation and maintenance of the system, whether it is installed on the roofs of buildings or the ground in those areas that currently require upgrading and/or are already affected by industrial exploitation (in compliance with the constraints affecting the island territory).

Another assumption is that the RES generators are able to automatically limit the power in case of surplus, whereas for underfrequency regulation (generation below the load), at least one diesel generator was set to be in operation, at any given time, to impose the grid characteristics and intervene as a reserve when necessary. Furthermore, no explicit consideration was given to the constraints of line transit or possible infrastructure adaptations necessary for the introduction of RES and system management.

For the comparison among scenarios, the reference parameter used is the LCOE, as deemed most fit to compare on an equal basis the effects of adopting different technical solutions, entailing different CAPEX and savings, which effect has to be accounted for during the whole lifetime of the project.

As for the financial assumptions, the project lifetime was set at 20 years, and the inflation rate at $0.5 \%$, based on 2018/2019 national data. The discount factor has been set at 5.31\%, calculated as the allowed Weighted Average Cost of Capital (WACC) for infrastructural investments in the electricity sector in the current period by the Italian regulatory agency, ARERA [18]. Similarly, the diesel price has been calculated with a formula provided by ARERA, that considers the market price for fuel and the distance to the nearest supply port [19], resulting in $0.62 € / 1$ price for Ustica in 2018.

Finally, the comparison does not account for possible financial incentives for certain RES.

\section{Scenario analysis}

\subsection{Generation side interventions}

As the island is characterized by high solar radiation, the first scenario involves the introduction of additional solar photovoltaic capacity, with the optimal size evaluated by simulating $100 \mathrm{~kW}$ increases until up to the physical constraint of 2.4 MW discussed above.

Fig. 2 shows that the LCOE decreases at most by $4.3 \%$ w.r.t. the base case, for a PV size of $1100 \mathrm{~kW}$; for higher PV capacities, we observe an increase in the energy surplus, i.e. non-dispatchable generation, with the consequent flattening of the RES penetration curve; therefore, the additional fuel savings no longer repay the increased investment costs.

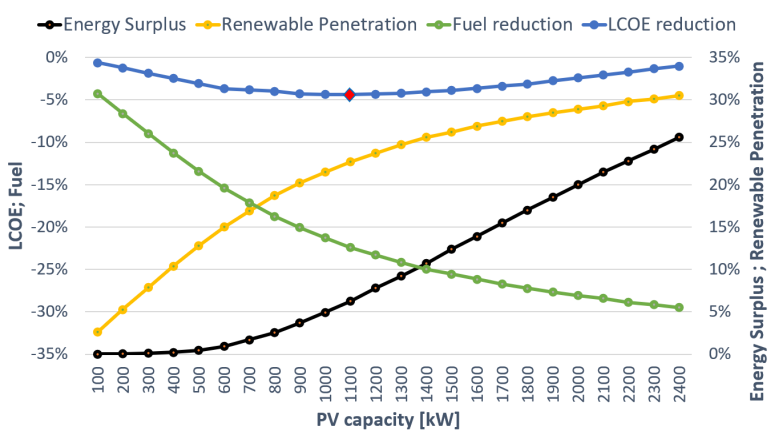

Fig. 2 First scenario: introduction of PV

The situation improves with the inclusion of a Li-ion storage system with 1:1 power/energy ratio which increases the flexibility of the system by time-shifting PV production and acting as an additional operating reserve that reduces the commitment of diesel generator units. For a set of PV capacities near the previously obtained minimum, the optimal battery sizing was determined, with the resulting LCOE reported in Fig. 3.

The new curve is not only shifted downward, meaning that adding the storage system results in lower LCOE in any case, but also to the right, showing that the least cost solution entails the installation of additional $\mathrm{PV}$. In particular, the best-case in this scenario includes 1.3 MW of PV with $700 \mathrm{kWh}$ of Li-Ion storage, reaching a $5.5 \%$ LCOE decrease w.r.t. the base case and a $27 \%$ renewable penetration. 


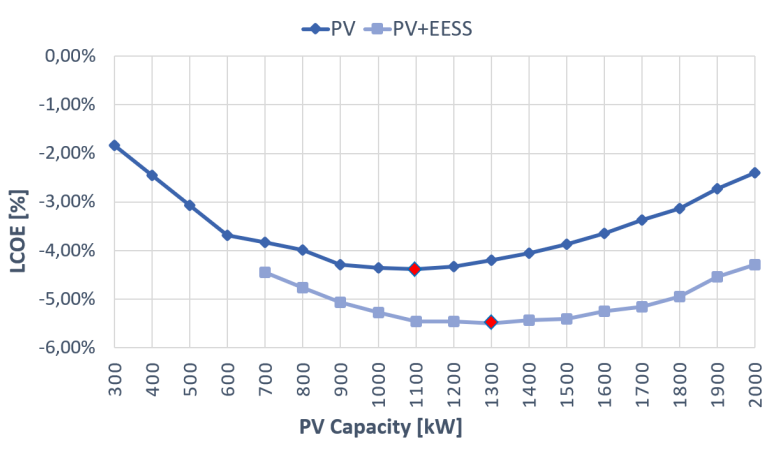

Fig. 3 Second scenario: PV plus electrochemical storage

For the foreseeable future, the installation of wind turbines in the island will not be allowed by the landscape protection policies; nonetheless, wind energy exploitation was considered by assuming a future authorization for turbines with a $\leq 30 \mathrm{~m}$ hub height, and less than $100 \mathrm{~kW}$ rating. Different combinations of number and size of wind turbines was simulated for four reference PV sizes, resulting in a best-case configuration of ten, $10 \mathrm{~kW}$ turbines paired to $1 \mathrm{MW} \mathrm{PV}$, as shown in Fig. 4. In this case LCOE is reduced by $6 \%$, despite an increase in non-dispatched energy. Even further LCOE reductions could be obtained by installing twenty $10 \mathrm{~kW}$ turbines, but the results have been discarded as this configuration would be too impactful on the landscape.

Finally, the impact of energy storage on the previous best-case scenario was assessed by including Li-Ion batteries at $250 \mathrm{kWh}$ increments, as reported in Fig. 5.

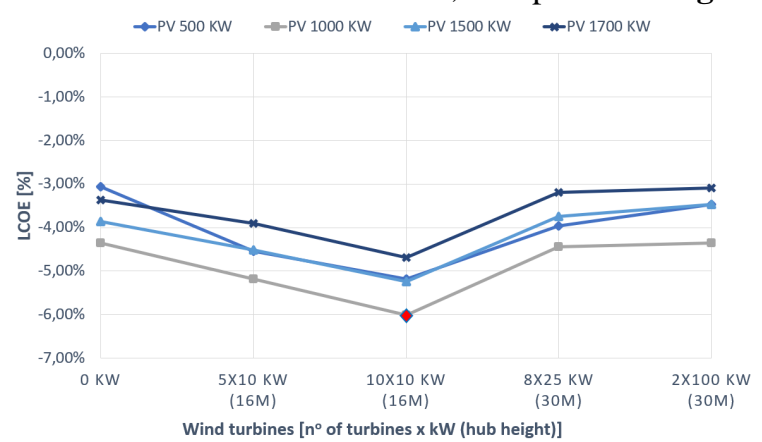

Fig. 4 Third scenario: PV plus mini-wind turbines

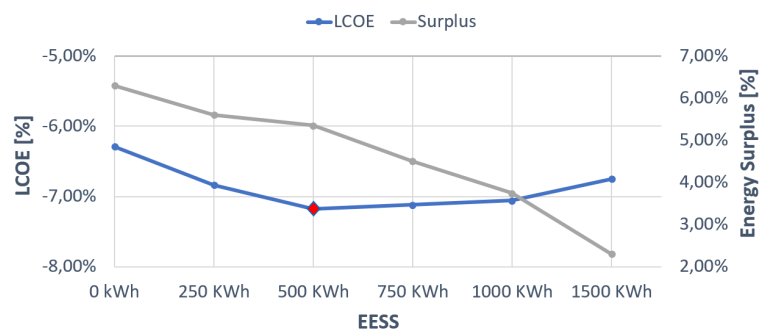

Fig. 5 Fourth scenario: 1 MW PV, $100 \mathrm{~kW}$ mini-wind and energy storage

Complementing PV and mini-wind with $500 \mathrm{kWh}$ Li-Ion batteries allows for a 7.3\% LCOE reduction w.r.t. the base case, resulting in the most convenient among the various generation side interventions investigated. The RES penetration for this case is about $25 \%$, circa the same of the PV plus storage configuration of Fig. 3, but realized with a $29 \%$ smaller energy storage system.

\subsection{Load side interventions}

In addition to generation-side interventions, further benefits can be achieved by an active management of the demand-side. The desalination plant is an obvious candidate, considering it amounts to almost a third of overall energy consumption, as seen in Fig. 1.

It was investigated whether the plant could be operated as a "deferrable load", i.e. to be met with a lower priority than the rest of the demand, as it is associated with a specific storage capacity. Actual water production/consumption data was not available, but the reverse osmosis plant kWh consumption for 2018 has been converted in an estimated number of $\mathrm{m}^{3}$ knowing its average conversion efficiency.

The proposed management strategy consists in concentrating the production of desalinated water (and therefore the energy absorption of the desalinator) during the hours of maximum RES production, exploiting the energy surplus to accumulate drinking water in the service tanks already present in the water supply network of the island. In particular, the primary storage tank is located in "Monte Costa del Fallo", next to the treatment facility, with a volume of $3000 \mathrm{~m}^{3}$. Assuming a production capacity of about $54 \mathrm{~m}^{3} / \mathrm{h}(1300$ $\mathrm{m}^{3} /$ day), against an average consumption of about 700 $\mathrm{m}^{3} /$ day, it is considered a daily water storage capacity of $600 \mathrm{~m}^{3}$ available to time-shift water production as needed. This volume is considered available at any given time taking into consideration that, along the water supply network, there are other water storage tanks for a total of $11000 \mathrm{~m}^{3}$ and that the peak water consumption never exceeded $1000 \mathrm{~m}^{3} /$ day.

Setting up a deferrable load in HOMER Pro requires the definition of its storage capacity; therefore, the 600 $\mathrm{m}^{3}$ volume was converted using the RO specific consumption of $7 \mathrm{kWh} / \mathrm{m}^{3}$, into an equivalent energy surplus of $4200 \mathrm{kWh} /$ day of the system.

In this scenario, the operation of the desalination system is similar to the time-shift of the batteries, but working on a mid-long term, with the water level in the tank high when there is greater renewable penetration, and lower in summer when the water demand increases and the renewable penetration is lower. Fig. 6, shows the trend of water volume within the $600 \mathrm{~m}^{3}$ assigned for deferring water production, obtained from converting back to $\mathrm{m}^{3}$ the $\mathrm{kWh}$ resulting from the simulations.

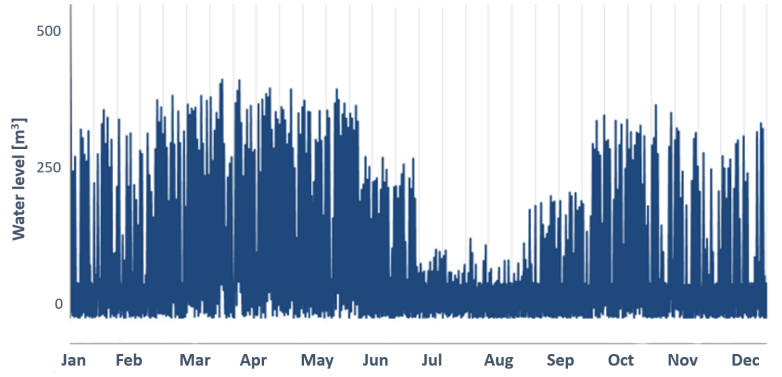

Fig. 6 Storage level associated to the deferrable load

With the simplifying assumption that this strategy could be implemented at negligible additional cost and limited complexity in the operation phase, results shows (Fig. 7) that considering the installation of PV alone, its 
optimal capacity increases by 55\% with DMS thanks to the reduced energy surplus.

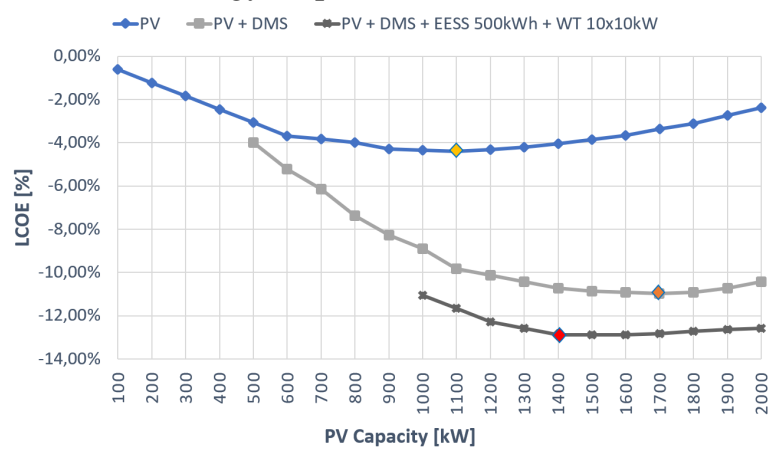

Fig. 7 Fifth scenario: the effect of DMS on the LCOE for the $\mathrm{PV}$ and $\mathrm{PV}+\mathrm{mini}$-wind+electrochemical storage scenarios

Furthermore, by integrating 10 wind turbines of 10 $\mathrm{kW}$ each, the optimal configuration consists of $1400 \mathrm{~kW}$ of PV and $600 \mathrm{~kW} / 600 \mathrm{kWh}$ Li-Ion batteries.

In this scenario, we observe the highest reduction in LCOE among all the cases $(-12,88 \%$ compared with the base case, almost double the reduction due to generation side intervention only), as well as in fuel consumption and greenhouse gasses emissions (-35\%). Taking into consideration the financial and economic assumptions this scenario presents an internal rate of return (IRR) of $17 \%$ with a payback period of 7 years, with respect to the business-as-usual.

\section{Sensitivity Analysis}

A sensitivity analysis was conducted to evaluate the robustness of the findings with respect to some of the variables and assumptions.

Firstly, a $\pm 10 \%$ variation of electricity demand and global horizontal irradiation have been tested for the different scenarios, with negligible effects on the LCOE. On the other hand, a strong dependence of results was observed on economic (diesel price) and financial parameters (WACC), which have therefore been investigated thoroughly. The PV plus storage scenario of Fig. 3 was taken as a reference, as it was considered the simplest to implement, even if better LCOE reductions can be achieved harnessing wind energy.

For the analysis, it was considered a $0.5 \div 0.9 €$ /liter price band for diesel, based on the price variation in the last 3 years and inclusive of transport surcharge; WACC was varied between $4 \%$ and $10 \%$ so as to represent different financial structures.

In Fig. 8, the LCOE for the base case and the PV plus storage system are reported; while the optimal PV size shows a quasi-linear variation with respect to the diesel price, the battery size surges at a fuel cost of $0.9 € / l$. The slope of the LCOE trendlines suggest that a decrease in fuel cost allows more savings for the hybrid system, while its increase entails a smaller increase in LCOE w.r.t. the base case; however, even if the cost of energy is still lower for a hybridized system with a high fuel cost, the higher CAPEX may discourage the investment.

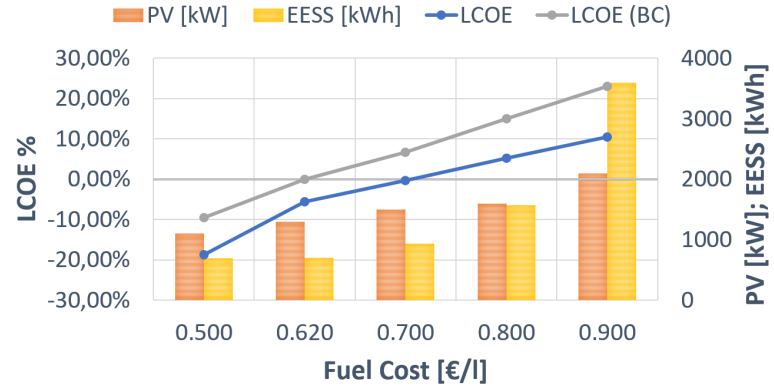

Fig. 8 Effect of fuel cost on the LCOE of the base case (BC) and the PV+battery system, reported with its optimal sizing

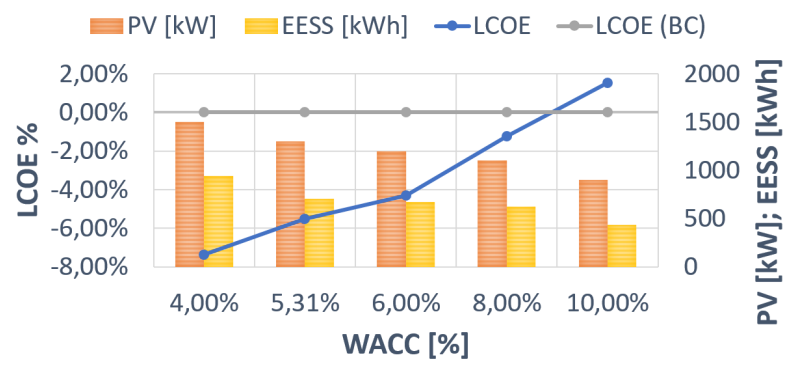

Fig. 9 Effect of WACC on the LCOE of the base case (BC) and the PV+battery system, reported with its optimal sizing

WACC variations, on the other hand, influence the feasible volume of investment but do not alter the optimal PV/battery ratio. They encourage higher investments when they are low and vice versa. Moreover, from Fig. 9 it can be seen that there is a threshold value for the discount rate beyond which the LCOE actually increases compared to the base case one, which obviously does not depend on WACC. These effects are confirmed by observing the simultaneous variation of fuel cost and WACC on the PV size, shown in Fig. 10, and the storage size, shown in Fig. 11.

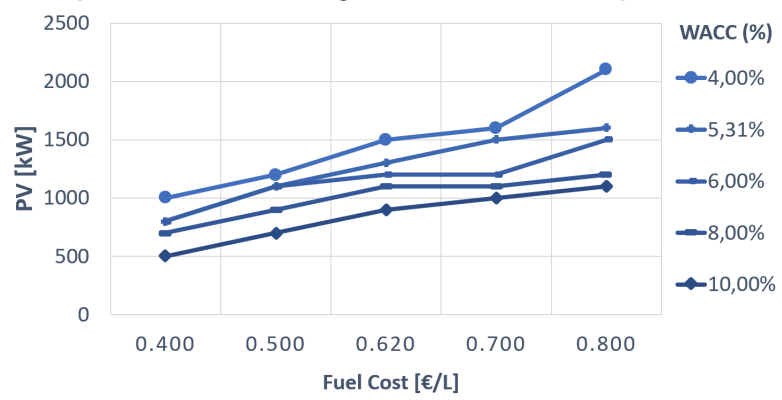

Fig. 10 Combined effect of fuel cost and WACC for the optimal size of the PV system

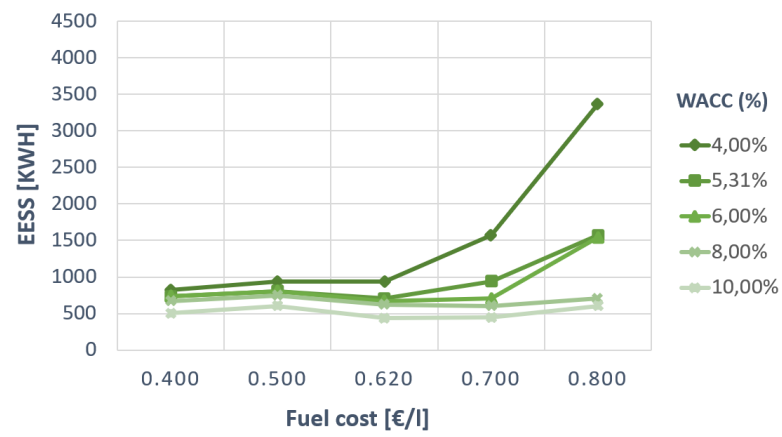

Fig. 11 Combined effect of fuel cost and WACC for the optimal size of the electrochemical storage system 
As for the PV, results confirm that optimal size increases as the fuel cost rises, but the WACC determines the appropriate volume of investment; at different discount rate corresponds a shifted set of PV sizes that have a similar trend among them. On the other hand, for the battery storage, as the fuel cost rises, the ideal amount of battery storage can be more than tripled if the investment conditions are very advantageous, with a $4 \%$ WACC. The savings allowed by electrochemical storage are increasingly less relevant as the WACC increases, as the corresponding installed PV plant is increasingly smaller, and because of the higher CAPEX that is not easily recovered by operational savings when the cost of capital is very high. For a WACC of $8-10 \%$, there is almost no dependence on the cost of fuel, as the whole intervention becomes uneconomic.

Considering the sensitivity analysis and the results of the optimization of the system components, it is clear that once the renewable potential and the ideal production mix have been identified, it is of fundamental importance to evaluate all those variables that can generate not only technical but also economic and financial risks. Assuming a limit discount rate of $8 \%$, the optimal size of photovoltaics is in the range 600$1400 \mathrm{~kW}$ depending on the price of fuel, while the optimal size of storage does not exceed $800 \mathrm{kWh}$.

In conclusion, Table 2 shows the optimal sizes of $\mathrm{PV}$ and battery designs resulting from three different financial structures (WACC) and two scenarios for fuel cost, one with the current price, and an increased one. The investment for the installation of the components and the savings related to power generation and system operating costs are also shown, with respect to the BC assets operating at the current or increased fuel price.

Table 3 - Sensitivity analysis results

\begin{tabular}{|c|c|c|c|c|c|c|}
\hline $\begin{array}{c}\text { Diesel } \\
{[€ / \mathrm{l}]}\end{array}$ & $\begin{array}{c}\text { WACC } \\
{[\%]}\end{array}$ & $\begin{array}{c}\text { PV } \\
{[\mathrm{kW}]}\end{array}$ & $\begin{array}{c}\text { EESS } \\
{[\mathrm{kWh}]}\end{array}$ & $\begin{array}{c}\text { CAPEX } \\
{[\mathrm{M} €}\end{array}$ & $\begin{array}{c}\text { LCOE } \\
{[\%]}\end{array}$ & $\begin{array}{c}\text { OPEX } \\
{[\%]}\end{array}$ \\
\hline 0.62 & $4 \%$ & 1500 & 940 & 2,7 & $-6,8 \%$ & $-16,8 \%$ \\
\hline 0.62 & $5.31 \%$ & 1300 & 707 & 2,31 & $-5,5 \%$ & $-14,7 \%$ \\
\hline 0.62 & $8 \%$ & 1100 & 623 & 1,96 & $-3,6 \%$ & $-13,1 \%$ \\
\hline 0.8 & $4 \%$ & 2100 & 3370 & 4,5 & $-10 \%$ & $-25 \%$ \\
\hline 0.8 & $5.31 \%$ & 1600 & 1570 & 3,11 & $-8,5 \%$ & $-20 \%$ \\
\hline 0.8 & $8 \%$ & 1200 & 707 & 2,16 & $-7,4 \%$ & $-15,8 \%$ \\
\hline
\end{tabular}

An additional evidence coming from the table is that the results are more sensitive to the fuel cost than to the WACC; comparing the results for the base case assumptions (Diesel 0,62 €/l; WACC 5,31\%) with the worst-case ones (Diesel 0,8 €/l: WACC 8\%), there are minimal changes in the design, while there is a more significant LCOE reduction for the second case where the investment conditions are less advantageous. However, the specific benefits of the hybridization have a stronger effect w.r.t. the base case, if this one is operating with higher fuel price.

\section{Conclusions}

In conclusion, for the specific case study, the installation of $1300 \mathrm{~kW}$ of photovoltaics and $700 \mathrm{kWh}$ of electrochemical storage is set forth as an intervention that is robust with respect to investment and economic conditions and is feasible in terms of regulatory, environmental and landscape protection constraints.

If it were possible to structure the financing so as to obtain a discount rate of $5.31 \%$ as assumed in this study, this configuration would lead to an energy cost reduced by $5.5 \%$ compared to the base case reducing system operating costs by $15 \%$. With an investment of $2.31 \mathrm{M} €$ the internal rate of return (IRR) is $8.5 \%$ with an economic payback time of less than 8 years.

By also integrating the desalination plant DSM, and with the addition of mini-wind turbines, it is estimated a further reduction of LCOE, up to $13 \%$.

In addition to the environmental benefits and added energy security, the economic savings resulting from the hybridization can contribute to reducing the reimbursements that are paid to the IEM through a dedicated tariff component at the national level. The benefits, therefore, concern the entire island community and by extension will also affect the national panorama.

We would like to thank the Ustica power company "D'Anna \& Bonaccorsi" for providing the data used in this paper.

\section{References}

1. IRENA, Global Renewables Outlook: Energy Transformation 2050. (2020).

2. A. Hirsch, Y. Parag, and J. Guerrero, "Microgrids: A review of technologies, key drivers, and outstanding issues," Renew. Sustain. Energy Rev., 90, March, (2018).

3. P. Blechinger, R. Seguin, C. Cader, P. Bertheau, and C. Breyer, "Assessment of the global potential for renewable energy storage systems on small islands," Energy Procedia, 46, (2014).

4. A. Corsini and E. Tortora, "Sea-water desalination for load levelling of gen-sets in small off-grid islands,” Energies, 11, 8, (2018).

5. European Commission, "Clean energy for EU islands,” (2017). [Online]. Available: https://ec.europa.eu/energy/topics/renewableenergy/initiatives-and-events/clean-energy-euislands_en. [Accessed: 25-Mar-2020].

6. J. K. Kaldellis and D. Zafirakis, "Prospects and challenges for clean energy in European Islands.The TILOS paradigm,” Renew. Energy, 145, (2020).

7. ENEA and ANCIM, Le Isole Minori Tra Sole, Mare e Vento. (2019).

8. Legambiente, "Isole sostenibili. Osservatorio sulle isole minori. Le sfide per le isole minori italiane e le buone pratiche nel mondo," (2019).

9. MISE, Decree for "Disposizioni per la progressiva copertura del fabbisogno delle isole minori non interconnesse attraverso energia da fonti rinnovabili." (2017).

10. Segreteria Generale Presidenza Regione 
Siciliana, "Le isole minori della Sicilia. Report, analisi, e valutazione dei flussi turistici," (2015).

11. D. Fioriti, R. Giglioli, D. Poli, G. Lutzemberger, A. Micangeli, R. Del, I. Perezarriaga, and P. Duenas-martinez, "Stochastic sizing of isolated rural mini-grids , including effects of fuel procurement and operational strategies,” Electr. Power Syst. Res., 160, (2018).

12. D. Fioriti and D. Poli, "A novel stochastic method to dispatch microgrids using Monte Carlo scenarios," Electr. Power Syst. Res., 175, December 2018, (2019).

13. A. Micangeli, R. Del Citto, I. Kiva, S. Santori, V. Gambino, J. Kiplagat, D. Viganò, D. Fioriti, and D. Poli, "Energy Production Analysis and Optimization of Mini-Grid in Remote Areas: The Case Study of Habaswein, Kenya,” Energies, 10, 12, (2017).

14. A. A. Setiawan, Y. Zhao, and C. V. Nayar, "Design, economic analysis and environmental considerations of mini-grid hybrid power system with reverse osmosis desalination plant for remote areas," Renew. Energy, 34, 2, (2009).

15. D. Airoldi, D. Bertani, E. Garofalo, S. Guastella, E. Lembo, C. Sandroni, and F. Giudici, "Scenari di sviluppo delle FER nelle isole minori italiane non interconnesse e analisi di casi studio,” RSE, (2017).

16. F. Giudici, A. Castelletti, E. Garofalo, M. Giuliani, and H. R. Maier, "Dynamic, multiobjective optimal design and operation of water-energy systems for small, off-grid islands,” Appl. Energy, 250, May, (2019).

17. Comune di Ustica, "Piano di Azione per l’Energia Sostenibile Isola di Ustica," (2015).

18. ARERA, Delibrerazione 2 Dicembre 2015, 583/2015/R/COM. (2015).

19. ARERA, "Documento per la consultazione 115/2018/R/EFR,” (2018). 